\title{
Should We Relinquish or Distribute the Benefits of Injustice?
}

Robert Huseby,

Department of Political Science,

University of Oslo

P.O. Box 1097 Blindern

0317 Oslo

Phone: +4722856287

Fax: +4722854411

(roberthu@stv.uio.no)

\begin{abstract}
In this paper I distinguish between two renderings of a beneficiary-oriented version of the Beneficiary principle (BP). According to the first version, beneficiaries of injustice have lesser claims to the part of their holdings that stem from injustice, than to the remainder of their holdings, and sometimes lesser than at least some other agents (apart from the victims). According to the second, beneficiaries of injustice have a duty to relinquish the part of their holdings that stem from injustice, because their claims to these goods are tainted. I claim that neither version is plausible. Against the first, I argue that while it is hard to assess in the abstract whether an innocent beneficiary has weaker claims to those of her holdings that stem from injustice, it seems nevertheless that no other agent (excluding the victim) has stronger claims to those holdings, which suffices to question the moral relevance of the view. Against the second, I hold that the duty to relinquish (whether decisive or not) is ultimately wasteful because it implies that benefits must sometimes be destroyed.
\end{abstract}

Key words: Benefiting from injustice - disgorging - relinquishing - injustice 


\section{Introduction}

Sometimes people innocently benefit from injustice towards others. For instance, most western consumers, even conscientious ones, make quite a few bargains on clothes and other goods that ultimately rest on injustice towards poor producers in other parts of the world. ${ }^{1}$ This, and many other examples, should make us wonder about the moral implications, if any, of benefiting from injustice. According to quite a few scholars, even innocently benefiting from injustice gives rise to duties of compensation. This is known as the beneficiary pays principle (BP). ${ }^{2}$

The BP can be specified and justified in various ways. For one thing, we can distinguish between victim-oriented and beneficiary-oriented versions of the principle. ${ }^{3}$ According to the victim-oriented version, the animating idea is the concern for the victim. Because she has suffered a loss as a result of injustice, she ought to be compensated. Once that is established, this view typically holds that a natural duty-bearer is the person who benefited, even if innocently, from the very same injustice that caused the victim to suffer the loss. ${ }^{4}$

The second, beneficiary-oriented version, however, assumes that there is something morally shady about benefiting from injustice. This shadiness can be cashed out in different ways. One might think that if some of my holdings result from an injustice, my right or entitlement to these holdings weakens, thus increasing the likelihood that some other agents have greater claims to these holdings. Alternatively, one might say that my claim to these holdings are tainted, and that it is important from a moral point of view that I rid myself of them, sooner rather than later. The details of such a view can differ, but the main point is that there is something about the beneficiary's relation to those of her holdings that result from injustice that is morally problematic.

The exact specification of the beneficiary-oriented view makes a difference in practice, however. For instance, if being in possession of fruits of injustice merely lessens my title to 
them, I might well keep these goods until someone else claims them, and keep them indefinitely if no one claims them. If the goods are relevantly tainted, on the other hand, it might be the case that I ought to get rid of them, even if I cannot give them back to the original owners. Further, as we will see below, different specifications will often rest on different justifications. Thus, the lessened title-specification is likely to be justified in a different way than the tainted claimsspecification. This means that rebutting one version might have no implication for the soundness of the other.

It is worth stressing that defenders of the beneficiary-oriented view need not be wholly insensitive to the force of the victim-oriented view. In fact, it would be somewhat peculiar to affirm the beneficiary-oriented view, while denying completely the victim-oriented view. The reason is that the victim's need for assistance or compensation seems, on the whole, morally more important than the beneficiary's potentially dirty hands.

In what follows, I will raise some critical questions pertaining to the beneficiary-oriented version of the BP. I start in the next section by distinguishing between different renderings of the principle. In section 3 and 4, I critically assess two such renderings (that I take to be representative). The last section concludes.

\section{Beneficiary-oriented Versions of the BP}

As indicated, there might be different reasons why people accept the view that beneficiaries of injustice have lesser claims to the goods that flow from injustice, than they have to other goods. And indeed, there might be different views on whether it is correct to (merely) say that beneficiaries have lesser claims to these goods, as opposed to saying, for instance, that such goods must be relinquished, discarded, or disgorged. ${ }^{5}$

To put it differently, there is a spectrum with regards to the moral shadiness of possessing fruits of injustice that ranges from the very weak idea that such fruits are (slightly) less rightfully 
yours than other goods you happen to possess, and the much stronger idea that such goods must be disgorged, even if the victim is no longer around to be compensated (and perhaps even if no one else is around). Further, it is clear that several different justifications are available for a number of different points along this spectrum.

As far as justifications are concerned, I will mention three that are found in the literature. First, we might think, as indicated, that we have lesser claims to those goods that flow from injustice. There might be different conceivable reasons for this, but one prominent example is due to Simon Caney. On his view, the unjust genesis of some holdings undermines entitlement to them, the upshot being that you are less entitled to holdings that stem from injustice, than you are to holdings that do not stem from injustice. ${ }^{6}$ To be sure, Caney's principle is part of a larger principle for distributing responsibilities to fight climate change, but it is clear how this reasoning might provide a rationale for a beneficiary-oriented version of BP. On such a view, moreover, we could imagine that others' claims, based on deprivation or (unrelated) victimhood would more likely trump our own claims to goods that result from injustice than our claims to goods that do not result from injustice. To be sure, this justification must be specified. We would have to know by how much our claims are reduced and what other agents might have stronger claims. The basic mechanics of the view is clear enough, however.

A different justification is indicated by Butt:

The individual's duty not to benefit from another's suffering when that suffering is a result of injustice stems from one's condemnation of the unjust act itself...[T]aking our nature as moral agents seriously requires ... that we hold a genuine aversion to injustice and its lasting effects. $^{7}$ 
On this view, it seems, moral agents ought to be averse (for moral reasons) to being in possession of goods that are the result of injustice. If we really have a duty not to benefit from the suffering that results from the injustice towards others, then we surely should not possess fruits of injustice, and we should disgorge them, if we cannot distribute them (presumably to someone who is not under the same duty not to benefit from others' suffering).

Note that Butt says several other things about benefiting from injustice, and some of them clearly point to the victim-centered view. Thus, the above quote does not do justice to Butt's exact view. My aim here is simply to present a possible defense for the beneficiary-oriented BP. Other defenses are conceivable, but it seems to me that the idea that we have a duty not to benefit from injustice against others (which is what Butt probably means here by 'another's suffering') is a plausible way to go.

A third justification for the beneficiary-oriented version of the BP is offered by Goodin. According to him it is noteworthy that disgorgement on the part of an innocent beneficiary removes goods from the wrong hands. ${ }^{8}$ The idea is that if an injustice occurs, the victim suffers a loss as a result, and some bystander benefits, we should ideally make sure that the beneficiary no longer benefits and the victim no longer suffers the loss. However, often it will be difficult to determine who should be compensated. In such cases, it is better to make sure that no one wrongly benefits, even if we cannot make sure that no one wrongly suffers a loss. Disgorgement represents a partial rectification of injustice. This justification is compatible with different views on the stringency of the duty to relinquish. ${ }^{9}$

To sum up so far, the beneficiary-oriented version of the BP comes in different strengths and with different justifications. I cannot discuss all possible versions in this paper. Instead, I will focus on two views, already suggested, that both seem representative of the broader class of BP views: 
1. Beneficiaries of injustice have lesser claims to the part of their holdings that stem from injustice (that have left the victim(s) deprived), than to the remainder of their holdings. ${ }^{10}$

2. Beneficiaries of injustice (that have left the victim(s) deprived), have a moral reason to relinquish the part of their holdings that stem from injustice.

These views are both moderate, and capture the two distinct modes of the beneficiary-oriented BP that are addressed here. ${ }^{11}$ I take it that the first can be justified with reference to a Caneytype justification, while the second can be justified with reference to a Butt- or Goodin-type justification. ${ }^{12}$ Further, something along the lines of 1 is clearly defended by Caney, and something along the lines of 2 is clearly defended by Goodin and Goodin and Barry. ${ }^{13}$

The distinction between victim-oriented and beneficiary-oriented versions of the BP may sometimes seem a bit blurred. In many cases it will be hard to evaluate whether or not a BPview is driven primarily by a concern for the victim, or primarily by a concern with the innocent beneficiary's moral relation to fruits of injustice that happen to be in her possession. There might be many different ways of drawing the line between the two types of principle. In this paper, however, I will assume that beneficiary-oriented versions are versions that are not fundamentally altered by the presence or absence of the victim (of the injustice that the beneficiary benefited from). ${ }^{14}$ Thus, beneficiary-oriented versions must have some force even in situations in which the victim is no longer around.

In the following two sections, I will voice some skepticism towards the beneficiary-oriented version of the BP. It is worth noting at the outset, however, that the motivation behind this skepticism is not that it is morally in order to leave the victim with the costs of injustice. Rather, the motivating idea is that, since the beneficiary, after all, is innocent, it is unclear why the 
beneficiary in particular, rather than other bystanders, should have special duties to cover (all) the costs. ${ }^{15}$

\section{Should Beneficiaries of Injustice Relinquish their Benefits?}

Let us start with the stronger of the two versions outlined above. On this view, beneficiaries of injustice have a moral reason to relinquish their benefits. Preferably, the benefits should be transferred to the victims. Importantly, however, benefits should be relinquished even in the absence of a victim to compensate. ${ }^{16}$ As indicated, there might be different reasons behind such a view, but I take it that the driving idea is that we have a moral reason not to profit from the injustice suffered by others. ${ }^{17}$ It is wrong or impermissible from a moral point of view that people possess goods or receive benefits that stems from injustice.

There are two interestingly different versions of this view. According to the first, having benefited from injustice is a decisive moral reason to relinquish the benefits. According to the second, having benefited from injustice is a defeasible reason to relinquish the benefits. Intuitively, the latter version is the more reasonable one. I assume that most defenders of the beneficiary-oriented $\mathrm{BP}$ will be attracted to the more moderate version.

This view, even though it is quite strong and demanding, has some intuitive support. Suppose for instance that you are in possession of some piece of art that you discover was taken from a Jewish family by the Nazis during WWII. Most people would feel that their claim to this particular piece of art was morally tainted, and that they would be required to give it back to the rightful owners. Plausibly, many would even think that they had at least some reason to simply give it up, if no rightful owners were obtainable (and perhaps even if no museum or foundation was willing to take it off their hands).

Notice, however, first, that the view is general, and intended to cover more ground than some intuitively compelling cases. Thus, we need to consider a broader range of scenarios. ${ }^{18}$ 
Secondly, there are some considerations that speak in favor of relinquishing benefits of injustice that do not follow from the beneficiary-oriented BP. One such consideration stems from the system of property rights present in well-ordered societies. In most cases, we are under a legal duty not to be in the possession of stolen goods. We are also under a legal duty not to be in the possession of goods that have been erroneously delivered to us. ${ }^{19}$ None of these concerns are sufficient to undergird the BP, however. There are many cases of benefiting from injustice that are not cases of being in possession of stolen or erroneously delivered goods, and these cases must be scrutinized from a moral point of view. ${ }^{20}$

In the literature, several cases have been offered to gauge the plausibility of (different versions of) BP. Consider the following case, presented by Haydar and Øverland:

The Bribe Case: Adam and Sam are applying for the same job. It is certain that Adam will get the job since he is clearly the best candidate. Polly has a conflict with Adam and wants to make sure that he does not get the job. So she bribes members of the selection committee to make sure that they will not offer the job to Adam. The plot works and Sam gets the job as a result. (Let us assume also that it is no longer possible to reverse the decision and hire Adam, and that, had Sam failed to get the job, he would have obtained another job that pays $20 \%$ less.) $)^{21}$

It seems implied in this case that it is not possible simply to run the hiring process once more from scratch. Recall that we are here concerned specifically with the beneficiary-oriented version of the BP. On this view, Sam has some reason to relinquish his (additional) benefits, even in the absence of Adam. Ideally, of course, Adam should receive these benefits as compensation for the injustice he has suffered, but, as noted, the relinquishing is not conditional on Adam's being able to be compensated. ${ }^{22}$ Suppose that Adam, in his frustration, changes his 
name and flees to Argentina, never to be heard from again. It is unknown whether he flourishes or despairs in his new life. Does Sam still have a (moral) reason to relinquish $20 \%$ of his income for the foreseeable future?

One might be disturbed here by the presence of the corrupt employers. But it seems that on most versions of the $\mathrm{BP}$, the bribe is not a necessary factor. The result would be the same if Polly, instead of bribing the employers, attacked Adam on his way to the interview, making sure that he was hospitalized and unable to take part in the further hiring process. Again, the beneficiary-oriented BP would require (if Adam quickly recovered and still fled incognito to Argentina) that Sam should keep relinquishing $20 \%$ of his income for the foreseeable future.

As indicated, the principle may not require that Sam should relinquish the relevant benefits no matter what. That would only be the case if benefiting from injustice was a decisive reason to relinquish. If Sam would starve if he could only spend $80 \%$ of his income, or if he, were he to relinquish $20 \%$, would end up worse off than everyone else, most people would probably accept that these countervailing concerns are sufficient to override the reason he has to relinquish his benefits. Other such reasons are conceivable as well. In the absence, however, of any such reasons (or only weak such reasons) it seems that, on the principle under consideration, Sam should indeed relinquish $20 \%$ of his income.

We should also consider what relinquishing means, and what it takes to achieve it. The word itself points mostly to the act of getting rid of, or giving up, something. ${ }^{23}$ Thus, the important thing is that Sam stops having the excess $20 \%$ of his income. As we have seen, there are other, victim-oriented reasons to wish that the $20 \%$ could be transferred to Adam. But when that is impossible, what should be done with the benefits? Goodin and Goodin and Barry suggest that the thing to do with relinquished (or disgorged) benefits is to return them to the public coffers. ${ }^{24}$

It is not immediately clear that this is a viable option, however. This will depend on the reasons we have for claiming that the benefits should be relinquished in the first place, and what 
happens (morally) to the benefits that are relinquished. Suppose that we think that benefits should be relinquished on the grounds that the holder's claim to the goods is tainted because they ensue from injustice. If that is the case, it is not obvious that this taint simply washes off, even if the goods are handed over to the state. ${ }^{25}$ On the other hand, if we think that a person's claim to some holding disappears if the holding is a result of injustice, then it seems that the holding is now unowned. ${ }^{26}$ If it is unowned, it further seems that the state should take charge of it, as it might do with other unowned stuff.

While these remarks are inconclusive, it seems that there is something peculiar about the idea that benefits of injustice should simply be relinquished, especially when the victim of the injustice is no longer around. To be sure, it makes sense to distribute the fruits of injustice in light of some plausible principle of justice. Goodin suggests that distribution can sometimes serve as an approximation of the requirements posed by (various forms of) corrective justice. ${ }^{27}$ This is no doubt true, but my suggestion here is that distribution might, on its own, be more plausible than a principle requiring that we relinquish the fruits of injustice (or more generally, more plausible than beneficiary-oriented versions of the BP).

It might be useful to consider the question in less institutionalized contexts. Consider the strange world SW that is inhabited by 12 persons (P1 - P12). As it happens $\mathrm{P} 1$ is a very crooked fellow, and he commits a grave injustice against P2. As a direct consequence of this injustice, P3-P12 all benefit significantly. Immediately after the injustice, however, P1 and P2 die from natural causes. We are left with a world populated by 10 individuals who have all benefited substantially from injustice. I have not provided details about the injustice here. These details can be filled out in various ways, but I assume that the injustice, and the ensuing benefits, is such that all adherents to the beneficiary-oriented BP would hold that the benefits ought to be relinquished. 
What should P3-P12 do? Clearly they have some reason to relinquish their benefits. As noted, a strong version would hold that they had decisive reason to relinquish. But even on the more moderate version, they should relinquish if no other reasons intervene. Suppose however, that none of P3-P12 would despair without the extra benefits. Further, they are not very unequally well off, and there are no other compelling reasons for them not to relinquish. In that case, it seems, they should, indeed, relinquish.

One could imagine different ways in which the relinquishing can be carried out. First, they could all, even if they are stateless, put all the benefits that they have gained from injustice, in a common pool, and then distribute it according to need, according to welfare, or in line with the result of some fair lottery. Secondly, they could simply swap benefits. P3 passes his benefits over to P4, and so on, until P12 passer her benefits over to P3. Third, they could all destroy their (unjust) benefits.

It seems to me that the first option, while perhaps reasonable, might come in two versions. According to the first version, the fruits of injustice should be distributed if possible, and if that is not possible, the beneficiaries get to keep them. According to the second version, the fruits of injustice should be distributed if possible, and if not, we should move on to option two or three. The first of these is not, in my view, really a relinquishing view, since it accepts too easily that the fruits of injustice stays in the wrong hands. This view, then, falls outside the scope of my discussion. The second is, however, a recognizable relinquishing view. In some cases, this view will, as stipulated, resort to swapping or destruction (more on which below).

The second option, swapping goods, seems pointless. If swapping fruits of injustice is sufficient to clean tainted claims, the principle does not seem to carry much moral weight. This looks more like a loophole than a way of honoring a moral requirement. Notice, however, that the challenge can be sharpened by supposing that SW only contains (initially) three individuals P1-P3. In this version, it is only P3 who benefits, and only P3 who survives. Clearly, there is 
no way for P3 to either distribute or swap goods. It seems then, that the second option threatens to collapse into the third.

What should we think about the third option then? We might hold that there is something morally suitable about relinquishing the fruits of injustice (if no compelling reasons tell us otherwise) even if the goods then will benefit no one. In my view, however, the third option points to an unattractive feature of the beneficiary-oriented version of the BP. It is eventually and ultimately wasteful, in a way that seems unacceptable. ${ }^{28}$ It is unclear how the title to goods or benefits can be tainted to the extent that we have some reason to discard them altogether, rather than to distribute them (if the victim is not around) or simply enjoy them (if the victim is not around and there is no pressing need for redistribution).

Note that the defenders of beneficiary-oriented versions of the BP do not spell out this wasteimplication explicitly. I take it, nonetheless, that this form of waste is an implication of a charitable reading of principles that find it somehow wrong that an innocent beneficiary retains her fruits of injustice. It seems reasonable to think that such views hold that there is a reason to waste the fruits of injustice in some circumstances, even if this reason is not decisive, and that this reason (for it to be a reason at all) wins out when no countervailing reasons are present. According to Goodin, for instance, “...disgorgement is an important aspect of corrective justice in its own right: it gets things out of the hands of people who wrongly possess them. If that is all we can do, we should do that much." ${ }^{29}$ This quote supports (at least) my charitable moderate interpretation: If goods are in the wrong hands, and we have reason to remove the goods from these hands, then surely we have a reason, even if defeasible, to do so, even if removal necessitates waste.

It could be argued that aversion to waste itself would count as an ever-present reason against destroying ill-gotten benefits, and that this reason always prevails. This would, in my view, be a contrived argument. If we think that benefits stemming from injustice should be relinquished 
(if the victim is no longer around), it would be strange to say that the aversion to waste always overrides the duty to relinquish when there is no one to compensate or distribute to. In my view, the version of the beneficiary-oriented BP discussed in this section is untenable (even though the principle would in practice not require destruction of goods very often). ${ }^{30}$

\section{Do Beneficiaries of Injustice Have Lesser Claims to the Unjust Part of Their Holdings?}

This version of the beneficiary-oriented BP is more moderate than the one discussed above. It also lacks the problematic waste-feature. On this view it is the case that whatever part of A's holdings that stem from injustice, A has a lesser claim to this part than to the remainder of her holdings. Two things are worth pointing out immediately. First, it seems hard to prove conclusively that A does not have lesser claims to those of her holdings that stem from injustice. Suppose that someone argued that the claims to these holdings were just imperceptibly weaker, and never overridden by others. Such an argument would be almost impossible to refute. Second, regardless of how much weaker the claims are, this version of the beneficiary oriented BP would be largely irrelevant if there are never any other agents with claims that outweigh the beneficiary's. For this to be an interesting and relevant view, then, it must sometimes be the case that a beneficiary's claims to those of her holdings that stem from injustice are weaker than at least some other agent's claims to that part of A's holdings. On many accounts of the $\mathrm{BP}$, of course, the victim has stronger claims to the beneficiary's holdings that stem from injustice towards her. But as noted above, if the beneficiary-oriented version is to have independent clout, it must have some force even in the absence of the victim.

Let us grant, for the sake of argument, that A's claim to those of her holdings that stem from injustice really is weakened. ${ }^{31}$ What other groups of agents might have stronger claims to those resources (apart from the victim)? I cannot assess all possibilities here, but three categories that seem plausible are a) people who have been the victims of unrelated injustices, b) people who 
have been the victims of accidents (of various kinds), and c) people who are deprived in absolute terms. Now, to have a scenario in mind, consider a version of the case discussed above:

Attack case: Adam and Sam are applying for the same job. It is certain that Adam will get the job since he is clearly the best candidate. Polly is a hardened mugger who incidentally attacks and robs Adam the night before the interview. Adam is severely injured and is hospitalized for a week. Sam gets the job as a result. He subsequently earns more than he would otherwise have earned. He is also in general happier than he would have been in his old job. In terms of value, the increased income and the increased happiness is equivalent to $25 \%$ of his current income. Adam later recovers and flees the country, and there is no way of getting hold of him.

In this case, Sam clearly benefits from injustice. It is also clear that whatever he benefits in material and immaterial terms, is not properly owned by someone else. Now, let us consider the groups of agents mentioned above. In my view, given the logic of BP, the most likely group to have claims to Sam's fruits of injustice are other victims of injustice (but I will consider the other groups in turn). Suppose Victor is the victim of an injustice, and that he is as a result worse off than he would otherwise have been. Assume that he was wrongly denied a job that would have made him substantially better off. For simplicity, imagine that he has lost in material and immaterial terms, the equivalent of $25 \%$ of Sam's earnings. Does Victor now have claims to $25 \%$ of Sam's earnings that exceed Sam's own claims? In my view, this would not be plausible.

To see this, suppose that we take into account certain other factors. ${ }^{32}$ Suppose for instance that even after his loss, Victor is much better off than Sam is. Or suppose that even after his 
good fortune, Sam is still worse off than most others (even though they have not benefited from injustice). In these cases, it does not seem right that Sam should compensate.

Further, imagine a real-life version of the scenario. For all you know, you might have gotten your actual job as a result of injustice. Some potentially successful applicant might have been unjustly barred from even applying. Or even more realistically, some potentially successful applicants may not have had access to relevant, high-quality education. Suppose it was now uncovered that this was the case, and that the victim of that particular injustice had disappeared. Would it seem plausible that you should now give $25 \%$ of your earnings to some other victim of injustice? Or perhaps it is easier to imagine that the case involves a colleague. Would you, if asked, advise your colleague in such a situation to start transferring $25 \%$ of her income to a victim of injustice? Would that really be what justice requires? In my view, this is not the case. Not because the victim should not be assisted, but because the moral connection between your colleague and the victim of (some unrelated) justice, is not sufficient to make it the case that she should take the whole burden. All in all, then, it does not in general seem convincing that innocent beneficiaries of injustice have lesser claims to the part of their holdings that stem from injustice than victims of unrelated injustices do.

What about victims of accidents? It seems very unlikely that such victims should have stronger claims to the fruits of injustice than the innocent beneficiaries of those fruits, if it is not the case that victims of unrelated injustices have such stronger claims. The reason is that the $\mathrm{BP}$, in general, sees a particular normative force in being the victim of injustice, but is largely silent on the moral significance of being the victim of simple accidents. Thus, victims of accidents are less likely than victims of injustice, to have stronger claims to the fruits of injustice than the beneficiary. To stick with the running example, it does not seem plausible that Sam should give $25 \%$ of his earnings to Fallon who lost a great job due to bad luck (she fell and injured herself and was hospitalized the night before the interview). Again, this is not to deny 
that Fallon might be in need of assistance. It is just to deny that it is primarily Sam's job to assist her.

Lastly, what about the deprived? Most people agree that the deprived have strong claims for assistance. If it is the case that the beneficiaries of injustice have lesser claims to their fruits of injustice than to their other holdings, it could be true that beneficiaries of injustice should compensate the deprived. Again, however, this sounds too quick. What about the rich and the beneficiaries of good brute luck ${ }^{33}$ Now, it could be the case, of course, that there are many ways of lessening the title to portions of one's goods. And perhaps benefiting from injustice is just one of them, and that being rich and lucky are others. If so, however, a very detailed account is needed. Again, we should ask whether such an account is likely to be more plausible than a more general distributive view. Such general distributive views, moreover, may be sensitive both to how well off people are, and also to the degree to which they are responsible for their level of welfare.

The above remarks, in my opinion, provide reasons to be skeptical of the lesser-claim version of the beneficiary oriented BP. They are not however, conclusive. First, I have not shown that a beneficiary of injustice does not have lesser claims to those of her holdings that stem from injustice. Doing so, moreover, would be quite difficult. Second, I have not shown conclusively that some other groups of agents do not have stronger claims to such unjust holdings. I have, however, provided some reasons to doubt that what I take to be the most likely candidates, have stronger claims to beneficiaries' fruits of injustice.

Lastly, I would like to point to a general concern. The view under scrutiny would make people vulnerable to suffer sudden large losses, even when this is avoidable. To be sure, Adam, Victor and Fallon have all suffered such losses, but due to aggressors or bad luck, not moral principles. As I have indicated throughout, there is an alternative to the BP (in all versions, but here again I am interested in the beneficiary-oriented view), and that is to distribute. Rather 
than having the innocent beneficiary pay the whole (or the brunt of the) compensation to unfortunate victims of injustice, the burden could rather be shared among all capable individuals in society, including, of course, innocent beneficiaries.

\section{Concluding Remarks}

In this paper, I have assessed two versions of the beneficiary-oriented BP. According to the first version, beneficiaries of injustice have lesser claims to the part of their holdings that stem from injustice, than they have to the remainder of their holdings. According to the second, beneficiaries of injustice have a duty to relinquish the part of their holdings that stem from injustice. I have argued that neither version is plausible. Against the first, I have argued that while it is hard to assess in the abstract whether an innocent beneficiary has weaker claims to those of her holdings that stem from injustice, it seems nevertheless that no other agent (excluding the victim) has stronger claims to those holdings, which suffices to question the moral relevance of the view. Against the second, I have argued that the duty to relinquish (whether decisive or not) is ultimately wasteful because it implies that benefits must sometimes be destroyed. While my discussion is far from complete, in the sense that there may be several distinct versions that I have not addressed, the present evaluation still strongly indicates that the beneficiary-oriented version of BP does not have much going for it. ${ }^{34}$ 
Notes:

1. Note that many examples of benefiting from injustice are intergenerational in the sense that (some of) the beneficiaries are born after the injustice has taken place. Such examples include colonization and climate change. Intergenerational cases might give rise to the non-identity-problem, according to which (on one interpretation) one cannot benefit from an act that belongs to the set of necessary conditions for one's existence (See Simon Caney, "Cosmopolitan Justice, Responsibility and Global Climate Change," Leiden Journal of International Law 18 (2005): 747-75; Derek Parfit, Reasons and Persons (Oxford: Oxford University Press, 1984). In this paper, I do not take into account the nonidentity problem, and will mostly use intragenerational cases. Note also that the question of whether injustice has contributed to the allocation of current holdings raises massive practical and epistemic challenges. I disregard these here in order to focus on some principled points. The reason is that BP will also be applicable in contexts in which it will be practically and epistemically manageable.

2. Or simply the beneficiary principle. See Daniel Butt, "On Benefiting from Injustice," Canadian Journal of Philosophy 37 (2007): 129-52; Daniel Butt, Rectifying International Injustice - Principles of Compensation and Restitution Between Nations (Oxford: Oxford University Press, 2009); Daniel Butt, “AA Doctrine Quite New and Altogether Untenable': Defending the Beneficiary Pays Principle," Journal of Applied Philosophy 31 (2014): 336-348; Robert E. Goodin, "Disgorging the Fruits of Historical Wrongdoing," American Political Science Review 107 (2013): 478-491; Robert Goodin and Christian Barry, "Benefiting from the Wrongdoing of Others," Journal of Applied Philosophy 31 (2014): 363-376; Axel Gosseries, "Historical Emissions and Free-riding," Ethical Perspectives 11 (2004): 30-60; Bashshar Haydar and Gerhard Øverland, "The Normative Implications of Benefiting from Injustice,” Journal of Applied Philosophy 31 
(2014): 349-362; Robert Huseby, "Should the Beneficiaries Pay?" Politics, Philosophy \& Economics 14 (2015): 209-225; Kasper Lippert-Rasmussen, “Affirmative Action, Historical Injustice, and the Concept of Beneficiaries," The Journal of Political Philosophy 25 (2017): 72-90; Carl Knight, "Benefiting from Injustice and Brute Luck," Social Theory and Practice 39 (2013): 581-598; Edward Page, “Give it Up for Climate Change: A Defense of the Beneficiary Pays Principle,” International Theory 4 (2012): 300-330; Tom Parr, "The Moral Taintedness of Benefitting from Injustice," Ethical Theory and Moral Practice 19 (2016): 985-997; Avia Pasternak, "Voluntary Benefits from Wrongdoing,” Journal of Applied Philosophy 31 (2014): 377-391.

3. See Holly Lawford-Smith, "Benefiting from Failures to Address Climate Change," Journal of Applied Philosophy 31 (2014): 392-404; Parr, op. cit., p. 987.

4. Note that most theorists, reasonably, agree that if the perpetrator of injustice is still around, she has even stronger duties to compensate.

5. I suppose throughout that the beneficiary-oriented BP imples that to the extent that the beneficiary is required to give up goods, she should do so equivalent to the value of the benefit, whether or not this corresponds to the (originally) wrongfully held objects (or its derivatives).

6. See Simon Caney, "Climate Change and the Duties of the Advantaged" Critical Review of International Social and Political Philosophy 13 (2010): 203-28, p. 216.

7. Butt, 2009, op. cit., pp. 127-128.

8. See Goodin, op. cit., p. 478.

9. A similar view is found in Goodin and Barry, op. cit., pp. 366-368. See also Parr, op. cit., p. 994. Holly Lawford-Smith also hints at a beneficiary-oriented view, but settles eventually for an explicitly victim-oriented version of the BP (See Lawford-Smith, op. cit., p. 399). 
10. As will become clear below, this view is arguably only relevant to the extent that some other agents (apart from the victim of the injustice) sometimes have greater claims to the fruits of injustice than the beneficiary has.

11. There might of course also be other such modes.

12. Note that justifications for 2 will most often also incidentally be justifications for 1 . If I have moral reason to relinquish a holding, it seems reasonable to assume that I have a lesser claim to this holding than to those of my holdings that I have no moral reason to relinquish.

13. See Caney, 2010, op. cit., p. 216; Goodin, op. cit., p. 482-484; Goodin and Barry, op. cit., pp. 363-364. Notice, however, that Goodin and Barry are more concerned with the implications of this view than with its justification.

14. To be sure, the absence or presence of the victim may make some difference, even on the beneficiary oriented view. All else equal, it would seem that the innocent beneficiary's duty to relinquish is stricter if the victim is present, than if the victim is absent.

15. I accept, as noted, that (non-innocent) perpetrators have special duties to compensate the victim.

16. See Goodin and Barry, op. cit., p. 367.

17. See Butt, 2009, op. cit., pp. 127-128.

18. It is worth noting, however, that some defenses of the BP are conditional. Haydar and $\emptyset$ verland, op. cit., argue that the principle is mainly relevant in the presence of further so called boosting conditions. Barry and Wiens hold that beneficiaries gain duties to compensate only when '...receiving and retaining the benefits sustains wrongful harm' (Christian Barry and David Wiens, "Benefiting from Wrongdoing and Sustaining Wrongful Harm,” Journal of Moral Philosophy 13 (2016): 530-552, p. 533). I focus on more general views in this paper. 
19. See Goodin and Barry, op. cit., p. 364.

20. See Knight, op. cit.

21. Haydar and Øverland, op. cit., 352. I take it that many defenders of BP would hold that the principle applies to this case. As noted above, however, Haydar and Øverland's view is special in the sense that they think that additional factors are necessary for the beneficiary to gain compensatory duties. In this case, it is the fact that a structured competitive setting (applying for a job) is upset, which boosts the beneficiary's duty. However, it is plausible that most adherents of the principle accept that Sam gain duties towards Adam merely in virtue of benefiting from injustice.

22. See Goodin and Barry, op. cit., p. 364.

23. See Goodin, op. cit., p. 478 .Note that Goodin primarily is concerned with disgorgement, which in his terminology is an object-oriented view (as opposed to person-oriented). My use of the term 'relinquish' rather than 'disgorge' is intended to signal that the distinction between object- and person-oriented is not vital to the current paper.

24. See Ibid., p. 487; Goodin and Barry, op. cit., p. 367.

25. This is not to deny that possibility, however. Some might think that taint, with time, will eventually wash off.

26. See Goodin, op. cit., p. 487.

27. See Ibid., pp. 478-491.

28. Something similar can be said about theories of absolute desert. A person might be better off than she morally ought to be, and it could be the case that it would be better (whether in one respect or all things considered) if she were worse off.

29. Ibid., p. 484.

30. Parr states explicitly that his account is subject to a non-waste restriction (See Parr, op. cit., p. 993, footnote 15). As indicated in the main text, I am not convinced that such a 
restriction is plausible. To be sure, it is intuitively plausible to avoid waste, but it is not clear how this should measure up against the wrongness of benefiting from injustice. According to Parr, a “... good is morally tainted when the recipient's possession of it is the intended result of injustice (Ibid., p. 994, emphasis in original)." Further, he holds that "[w]e can explain the normative significance of the moral taintedness by reference to the idea that, in refusing to relinquish the good or the benefit it yields, the recipient allows the wrongdoer to complete her immoral plans (Ibid., p. 994)." One reason for this, Parr submits, is that it is impersonally bad for immoral plans to be realized (See Ibid., p. 994). In light of this explication of the badness of receiving and keeping tainted goods, the waste-restriction, at least in a general form, starts to appear implausible. It might be plausible not to relinquish a huge benefit from a modest wrongdoing, if relinquishing necessitates waste, but very implausible not to relinquish a moderate benefit from a massive and grave injustice, even if the benefit thereby goes to waste. Otherwise, the importance of keeping immoral plans from being realized starts to look negligible.

31. To repeat, this is to grant the lesser claims thesis as such, but not necessarily in an interesting version.

32. See Huseby, 2015 op. cit.; Knight, op. cit.; Lippert-Rasmussen, op. cit.

33. See Robert Huseby, "The Beneficiary Pays Principle and Luck Egalitarianism," Journal of Social Philosophy 47 (2016): 332-349;; Knight, op. cit.

34. This paper was presented at a conference on 'Benefiting from injustice' at the Center for the Study of Mind in Nature at the University of Oslo in 2016. I am very grateful to Daniel Butt, Alexandra Couto, Bob Goodin, Bashshar Haydar, Ole Koksvik, Sigurd Lindstad, Kasper Lippert-Rasmussen, Ed Page, and Ana Tanasoca for helpful comments. Work on this article has been supported by the Norwegian Research Council (Grant number: 222541). 